\title{
Identificação e Produção de Pigmento por Fungo Talaromyces sp.
}

\author{
Fabiane Ferreira dos Santos, Mariana Ruiz Frazão do Nascimento, Danielle Bruno \\ de Carvalho, Maria Helena Miguez da Rocha Leão e Priscilla Filomena Fonseca \\ Amaral
}

Universidade Federal do Rio de Janeiro - Escola de Química, Departamento de Engenharia Bioquímica. Av. Athos da Silveira Ramos, 149 - CT, Bloco E, Lab.103, Ilha do Fundão, CEP: 21941-909 - Rio de Janeiro, RJ, Brasil - E-mail: fabiane.sd@gmail.com

\section{RESUMO}

A cor é um atributo muito importante nos alimentos e, atualmente, é cada vez maior a restrição ao uso de corantes sintéticos, principalmente, pelas indústrias de alimentos devido seus efeitos indesejáveis. Assim, o interesse no desenvolvimento de pesquisas que envolvam produção e extração de corantes naturais vem crescendo. Algumas espécies de fungos filamentosos são capazes de produzir metabólitos secundários que podem ser utilizados como corantes e que apresentam diferentes tonalidades que variam entre vermelho, amarelo e laranja. Em função disso o principal objetivo desse trabalho foi isolar o microrganismo em meio apropriado, identificar a espécie produtora de pigmento, avaliar o corante produzido com varredura em espectrofotômetro e aperfeiçoar as condições para produção de pigmento. $O$ microrganismo isolado foi identificado como pertencente ao gênero Talaromyces. Após 10 dias de cultivo detectou-se a produção do corante vermelho em $\mathrm{pH}$ $6,0,26^{\circ} \mathrm{C}$ e $160 \mathrm{rpm}$ com absorção máxima de $497 \mathrm{~nm}$, demonstrando possibilidade de produção industrial.

Palavras - chave: produção, corante, natural, fungo

\section{INTRODUÇÃO}

Os corantes são amplamente utilizados pelas indústrias de alimentos, farmacêutica têxtil e de cosméticos, mas com o aparecimento de alergias e outras doenças diversas associadas ao uso de corantes sintéticos, além da atual preocupação ambiental, aumentou o interesse no desenvolvimento de pigmentos a partir de fontes naturais (HAILEI et al., 2011; MAPARI et al., 2005; RUIZ-RUIZ et al., 2013).

Alguns corantes naturais já são conhecidos e têm origem animal ou vegetal, contudo apresentam algumas limitações como disponibilidade em qualquer época do ano, sensibilidade ao calor, pH, luz, além de baixa solubilidade em água. Fungos são promissoras fontes naturais alternativas a essas substâncias, porque podem crescer rapidamente, tem alta produtividade, estabilidade e independem de condições climáticas. (SAMEER et al., 2006).

Recentes estudos relatam a utilização de fungos como potenciais produtores de diversos pigmentos e estes metabólitos secundários na maioria das vezes não tem função conhecida. Estes corantes não são diferentes somente pela estrutura química, mas pela 


\section{SIMPÓSIO DE BIOQUÍMICA E BIOTECNOLOGIA}

05 a 07 de agosto de 2015, Londrina - PR

VSIMBBTEC

Londrina 2015

ampla faixa de cores que podem produzir e pela aplicabilidade, porém são pouco explorados como possíveis produtores de corantes alimentares (MAPARI et al., 2009; MAPARI et al., 2010).

Diante do exposto, o presente trabalho objetivou apresentar informações sobre o isolamento, identificação e produção de corante fúngico a fim de potencializar o seu uso pelas indústrias.

\section{MATERIAL E MÉTODOS}

Isolamento e identificação - $\mathrm{O}$ isolamento dos fungos foi realizado a partir de solo contaminado com hidrocarboneto, através da técnica de diluições seriadas, onde uma pequena amostra de solo foi diluída em solução salina $\mathrm{NaCl} 0,9 \%(9 \mathrm{~mL})$. A segunda diluição $\left(10^{-2}\right)$ foi realizada transferindo-se $1 \mathrm{~mL}$ da diluição $10^{-1}$ para tubo de ensaio contendo $9 \mathrm{~mL}$ do diluente, e assim sucessivamente até a diluição $10^{-8}$. As amostras foram plaqueadas em placas de Petri contendo meio DAS (Sabouraud Dextrose Agar). As placas foram incubadas a $30^{\circ} \mathrm{C}$, durante 5 dias. A seqüência do isolamento foi realizada através da técnica de esgotamento por estrias. Os microrganismos isolados foram identificados quanto ao gênero pelas características microscópicas das colônias, após o preparo de microcultivos em lâminas. Para confirmação do gênero e da espécie de fungo isolado foi realizado um sequenciamento do DNA por eletroforese capilar no equipamento ABI 3500 Genetic Analyser e alinhamento das sequências de nucleotídeos com as sequências de referência depositadas no GenBank (Fungal Barcoding Consortium et al., 2011).

Produção de corante - Passado o tempo de incubação foi realizado o preparo do inóculo em ambiente estéril, através da adição de $5 \mathrm{~mL}$ de meio DAS e posterior raspagem da superfície com auxílio de uma alça de platina para obtenção de uma suspensão de esporos que foi recolhida para um tubo Falcon estéril. Essa suspensão de $5 \mathrm{~mL}$ contendo os esporos foi adicionada ao Erlenmeyer com $250 \mathrm{~mL}$ de meio Sabouraud líquido (sem agar) pH 6,0 e armazenado em incubador rotatório à $28^{\circ} \mathrm{C}$ e agitação de $160 \mathrm{rpm}$ para produção de corante. Após 10 dias o material do Erlenmeyer foi filtrado a vácuo em membrana filtrante de $0,45 \mu \mathrm{m}$, este filtrado foi utilizado posteriormente para análise espectrofotométrica do corante.

Análise da produção de corante vermelho - O pigmento vermelho foi avaliado indiretamente através da medição espectrofotométrica com leitura a 490nm que corresponde à máxima absorbância para os corantes vermelhos e para tal o meio foi varrido na faixa de 400 a $600 \mathrm{~nm}$ em cubeta de $1 \mathrm{~cm}$ à temperatura ambiente.

\section{RESULTADOS E DISCUSSÃO}

Foi realizado o isolamento dos fungos a partir do solo contaminado com hidrocarboneto. Identificou-se o fungo filamentoso produtor de corante pela visualização, a olho nu, da coloração vermelha no meio sólido onde o fungo cresceu (Figura 1a). 0 isolamento do fungo foi realizado e, em seguida, procedeu-se a realização de microcultivos, possibilitando identificação do fungo isolado através da análise microscópica dos micélios (Figura $1 \mathrm{~b}$ e c). $\mathrm{O}$ fungo foi identificado como pertencentes ao gênero Penicillium, em função da estrutura do corpo de frutificação. Para se ter certeza da espécie em questão foi realizado sequenciamento do DNA do micro-organismo por eletroforese. A partir então da sequência 


\section{SIMPÓSIO DE BIOQUÍMICA E BIOTECNOLOGIA 05 a 07 de agosto de 2015, Londrina - PR}

\section{VSIMBBTEC}

Londrina 2015

obtida foi feita uma comparação com um banco de dados de DNA. O resultado dessa comparação demonstrou maior identidade da amostra (99\%) com o fungo Talaromyces sp. (espécies Talaromyces sublevisporus, Talaromyces radicus).

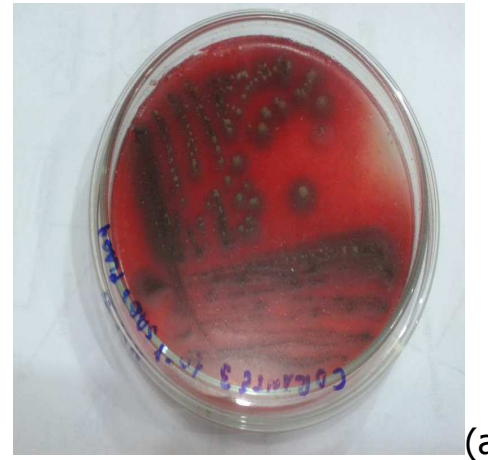

(a)

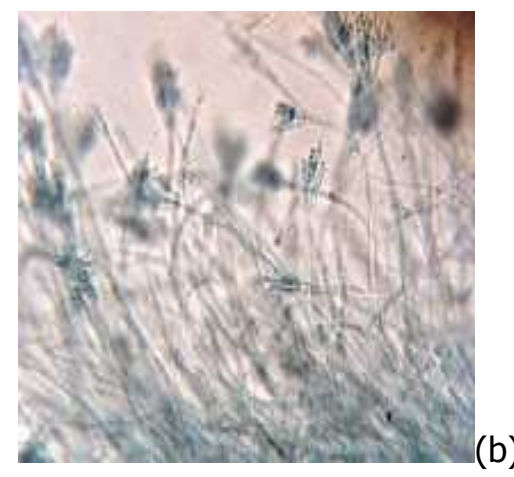

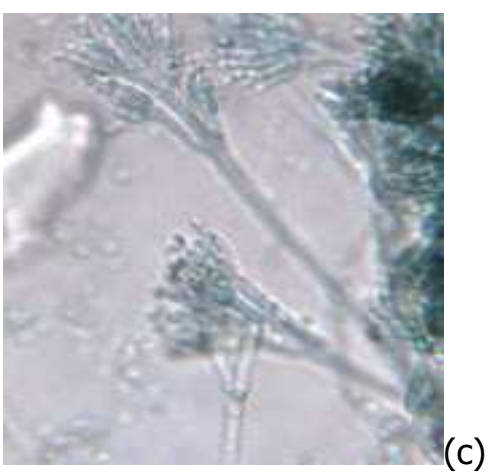

Figura 1 - (a) Meio DAS com fungo filamentoso produtor de corante (b) Aspectos morfológicos de Penicillium sp. (c) Conidióforos e células fialídias

De acordo com Gunasekaran et al. (2008), o crescimento do fungo Penicillium sp.e a produção de pigmentos foram maiores quando usadas temperatura em torno de $30^{\circ} \mathrm{C}$ e velocidades de agitação entre 150 e 200rpm. Portanto, essas condições foram utilizadas no presente trabalho para o fungo isolado.

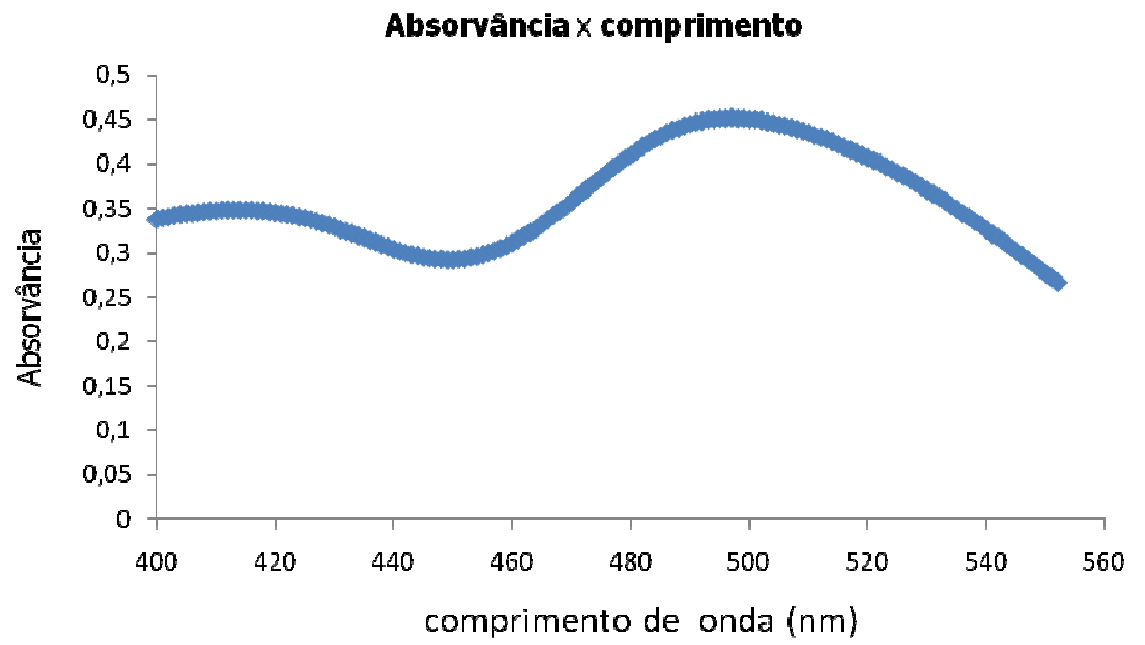

Figura 2 - Varredura de absorbância em função do comprimento de onda para o meio fermentado por Talaromyces $s p$. após filtração para remoção do fungo filamentoso.

O fungo filamentoso isolado de solo contaminado com hidrocarboneto e identificado com Talaromyces sp. foi cultivado em meio Sabouraud líquido a $28^{\circ} \mathrm{C}$ e $160 \mathrm{rpm}$. Após seis dias de cultivo, observou-se o início de uma coloração alaranjada que se intensificou com o 


\section{SIMPÓSIO DE BIOQUÍMICA E BIOTECNOLOGIA 05 a 07 de agosto de 2015, Londrina - PR}

VSIMBBTEC

Londrina 2015

decorrer do processo. No décimo dia, a coloração era vermelho intenso. Portanto, filtrou-se o cultivo para remoção do fungo e procedeu-se uma varredura de comprimento de onda em espectrofotômetro. Foi necessária uma diluição de 50 vezes para que os valores de absorbância ficassem inferiores a 0,5. A Figura 2 apresenta a varredura do comprimento de onda e a absorbância máxima encontrada para o corante obtido foi de 497nm. Gunasekaran e colaboradores (2008) produziram um corante por Penicillium sp. com absorção máxima em $530 \mathrm{~nm}$.

\section{CONCLUSÕES}

O microrganismo isolado foi identificado como pertencente ao gênero Talaromyces. Esse fungo filamentoso foi capaz de produzir um corante com coloração vermelha após dez dias de cultivo a $28^{\circ} \mathrm{C}$ e $160 \mathrm{rpm}$. O corante produzido apresenta absorção máxima em 497 nm, que está na faixa de absorção para o vermelho. Esse corante apresenta potencial para ser utilizado na indústria de alimentos.

\section{REFERÊNCIAS}

GUNASEKARAN, S.; POORNIAMMAL, R. Optimization of fermentation conditions for red pigment production from Penicillium sp. under submerged cultivation. African Journal of Biotechnology, v.7, n.12, p. 1894-1898, 2008.

HAILEI, W.; ZHIFANG, R.; PING, L.; YANCHANG, G.; GUOSHENG, L.; JIANMING, Y. Improvement of the production of a red pigment in Penicillium sp HSD07B synthesized during co-culture with Candida tropicalis. Bioresource Technology, v.102, p. 6082-6087, 2011.

MAPARI, S. A.S.; NIELSEN, K. F.; LARSEN, T. O.; FRISVAD, J. C.; MEYER, A. S.; THRANE, U. Exploring fungal biodiversity for the production of water-soluble pigments as potential natural food colorants. Current Opinion in Biotechnology,v. 16, p.231-238, 2005.

MAPARI, S. A. S.; MEYER, A. S.; THRANE, U. Photostability of natural orange, red and yellow fungal pigments in liquid food model systems. Journal of agricultural and food chemistry, v.57, n.14, p. 6253-6261, 2009.

MAPARI, S. A. S.; THRANE, U.; MEYER, A. S. Fungal polyketide azaphilone pigments as future natural food colorants? Tends in Biotechnology, v.28, n.6, p. 300-307, 2010.

RUIZ-RUIZ, F.; BENAVIDES, J.; RITO-PALOMARES, M. Scaling-up of a B-phycoerythrin production and purification bioprocess involving aqueous two-phase systems: Practical experiences. Process Biochemistry v. 48 p. 738-745, 2013.

SAMEER, A. M.; ANNE, S. M.; ULF, T. Colorimetric Characterization for Comparative Analysis of Fungal Pigments and Natural Food Colorants. Journal of Agricultural and Food Chemistry, v.54, p. 7027-7035, 2006. 